\title{
Big Five Personality Factors as Predictors of Organizational Citizenship Behavior: A Complex Interplay
}

\author{
Dr. Sairaj M. Patki ${ }^{1}$, Dr. Shobhana C. Abhyankar ${ }^{2}$
}

\section{ABSTRACT}

The present study investigated the Big Five personality factors as predictors of citizenship behaviors directed towards individuals (OCBI) and towards the organization (OCBO). The Big Five Inventory by Donahue \& Kentle (1991) and Organizational Citizenship Behavior Scale by Lee and Allen (2002) were used and the sample comprised of 325 clerical employees, from nationalized and co-operative banks in Maharashtra. Findings revealed that openness emerged as the strongest predictor of both OCBI and OCBO, followed by extraversion. Moreover, openness fully mediated the relationship between agreeableness and OCBI, whereas extraversion partially mediated the relationship between agreeableness and OCBI. Openness and extraversion also partially mediated the relationship between conscientiousness and OCBO.

Keywords: Big Five personality factors, OCBI, OCBO, mediation.

Barnard (1938) proposed that an organization that has employees who are willing to put cooperative efforts, essentially achieves its objectives effectively. This idea of cooperative efforts was further extended as extra-role behavior by Katz and Kahn (1966, 1978). Extending the idea of extra-role behavior from the work of Katz and Kahn, Organ and colleagues coined the term "organizational citizenship behavior” (OCB) (Bateman \& Organ, 1983; Organ, 1988). Organ (1988) defined organizational citizenship behaviors as behaviors of individual employees that are discretionary in nature, that are not directly or explicitly recognized within the framework of the formal reward system, and that consequently promote the effective functioning of the organization. In general, OCB has been linked positively to reductions in costs, improvements in efficiency, profitability, production quantity and customer satisfaction (Dunlop \& Lee, 2004; Koys, 2001; Podsakoff \& MacKenzie, 1994; Walz \& Niehoff, 1996, Yen \& Niehoff, 2004), and negatively to intentions to leave the organization and actual departures (Chen, 2005; Mossholder et al., 2005). However, factor analytical studies by Williams and

\footnotetext{
${ }^{1}$ Assistant Professor, Department of Psychology, Modern College of Arts, Science and Commerce, Shivajinagar, Pune, Maharashtra (India)

${ }^{2}$ Vice Principal and Head, Department of Psychology, Fergusson College, Savitribai Phule Pune University, Pune, Maharashtra (India)

*Responding Author

(C) 2016 I S Patki, S Abhyankar; licensee IJIP. This is an Open Access Research distributed under the terms of the Creative Commons Attribution License (http://creativecommons.org/licenses/by/2.0), which permits unrestricted use, distribution, and reproduction in any Medium, provided the original work is properly cited.
} 
Anderson (1991) show that OCB should be defined by its target. Their two-factor model of OCB thus differentiates between citizenship behaviors aimed at individuals / colleagues (OCBI), and those directed at the organization (OCBO) (Williams \& Anderson, 1991).

Among antecedents of OCB, employee personality has been the most prominently researched predictors of OCB (Bateman \& Organ, 1983; Organ, 1988; Smith et al., 1983). Findings of metaanalyses by Podsakoff et al. (2000), and Borman et al. (2001) revealed that conscientiousness emerged as the strongest predictor of OCB. Agreeableness too was found to predict OCB in three meta-analyses (Borman et al., 2001; Chiaburu et al., 2011; and Podsakoff, MacKenzie, Paine, \& Bachrach, 2000), whereas negative affectivity received support as a weak but valid predictor of OCB in some instances. Openness and extraversion were not considered in the three metaanalyses discussed earlier (Borman et al., 2001; Organ \& Ryan, 1995; Podsakoff et al., 2000). However, a fairly recent meta-analysis by Chiaburu et al. (2011) demonstrated openness as the strongest predictor of OCB, whereas extraversion emerged as the second best predictor of OCB after conscientiousness. In all these meta-analyses and in most other related studies, however, focus has predominantly been placed upon the five-factor model of OCB proposed by Organ (1988) that includes altruism, conscientiousness, sportsmanship, courtesy and civic virtue, whereas the two-factor model of OCB by Williams and Anderson (1991) has received little attention, and even more so in the Indian setup. According to Williams and Anderson (1991) behaviors included in OCBI may be equated to the dimension referred to as altruism in earlier literature (Organ, 1988). OCBO on the other hand may be equated to the dimension referred to as generalized compliance in earlier literature (Smith et al., 1983), as organizational obedience by Graham (1991), and as organizational compliance by Podsakoff et al. (2000). While agreeableness is associated with high levels of interpersonal competence (Witt et al., 2002) and effective collaboration in situations demanding joint action (Mount et al., 1998), conscientiousness reflects efficiency, organization, reliability, and thoroughness. This combined with the existing literature available on Organ's model of OCB, suggests that agreeableness can be expected to be the strongest predictor of OCBI, whereas conscientiousness can be expected to be the strongest predictor of OCBO. The present study thus investigated the role of personality factors as predictors of OCBI and OCBO.

\section{Hypotheses}

$\mathrm{H}_{1}$ : Conscientiousness, agreeableness, openness to experience, and extraversion are positively correlated with OCBI and OCBO.

$\mathrm{H}_{2}$ : Neuroticism is negatively correlated with OCBI and OCBO.

$\mathrm{H}_{3}$ : Agreeableness is the strongest predictor of OCBI.

$\mathrm{H}_{4}$ : Conscientiousness is the strongest predictor of OCBO. 


\section{METHOD}

\section{Sample}

Convenience sampling technique was used for the present study. Of the 550 distributed questionnaires, 399 questionnaires were received. After screening out incomplete questionnaires and questionnaires with inconsistent/casual response patterns, data of 325 employees (166 males and 159 females, Mean age - 43.26) across 11 nationalized and 9 co-operative banks, covering over 90 branches in Maharashtra, was retained for the final analysis.

\section{Tools}

All respondents were given a compiled questionnaire beginning with section for demographic details, general instructions, informed consent and then the tools, comprising of the 44 item Big Five Inventory (BFI) (John, Donahue \& Kentle, 1991) which measures the five factors of personality - neuroticism, extraversion, openness, agreeableness, and conscientiousness; and the16 item Organizational Citizenship Behavior Scale developed by Lee \& Allen (2002) which has 8 items each for individual-directed (OCBI) and organization-directed (OCBO) citizenship behaviors. High scores on subscales of BFI indicate a high tendency with respect to that personality trait. The reliability coefficients range from .79 for agreeableness to .88 for extraversion, with a mean coefficient of .83. A high score on OCBI and OCBO indicates a high frequency of demonstrating citizenship behaviors. Authors report alpha coefficient values .87 and .89 for OCBI and OCBO scales respectively.

\section{Statistical Analyses}

The data was tested for adherence to assumptions of sample size adequacy, linearity, collinearity, and independence of errors (Garson, 2012; Williams et al., 2013). Pearson's Product-moment correlation and regression analyses were performed using SPSS Ver. 22. Path analysis testing mediation was performed using Smart PLSVer. 3.2.1 (Ringle et al., 2015) and then Sobel test was performed using Daniel Soper's online statistical calculator.

\section{RESULTS AND DISCUSSION}

Table 1 Summary of Person's Product-Moment Correlation Coefficients between the Personality Dimensions and OCBI and OCBO $(n=325)$

\begin{tabular}{|cccccc|}
\hline & Conscientiousness & Agreeableness & Extraversion & Openness & Neuroticism \\
\hline OCBI & $.202^{* *}$ & $.175^{* *}$ & $.252^{* *}$ & $.361^{* *}$ & -.053 (NS) \\
OCBO & $.275^{* *}$ & $.245^{* *}$ & $.318^{* *}$ & $.432^{* *}$ & -.108 (NS) \\
\hline
\end{tabular}

$* *=p<.01 \quad \mathrm{NS}=$ not significant $(p>.05)$

As seen in Table 1, conscientiousness, agreeableness, openness to experience and extraversion were found to be correlated with both OCBI and OCBO. Thus hypotheses 1 was supported. Hypothesis 2, however, was not supported, as neuroticism was not found to be significantly correlated with either OCBI or OCBO. 
Earlier studies have upheld conscientiousness and agreeableness as the most prominent antecedents of OCB (e.g. Hurtz \& Donovan, 2000; Ilies et al., 2009; Organ \& Ryan, 1995). Multiple regression analysis was performed to test hypotheses 3 and 4 , excluding the insignificantly correlated neuroticism.

Table 2 Summary of Multiple-Regression Analysis for the Personality Dimensions and OCBI $(n=325)$

\begin{tabular}{|lccccccc|}
\hline \multicolumn{1}{|c}{ Predictor } & $\mathbf{R}$ & $\mathbf{R}^{2}$ & ANOVA & \multicolumn{4}{c|}{ Coefficients } \\
\hline Conscientiousnes & .387 & .150 & $14.127^{* *}$ & .150 & .016 & 0.256 & .789 \\
S & & & & & & & \\
Agreeableness & & & & .606 & .069 & 1.160 & .247 \\
Extraversion & & & & .988 & .122 & 2.152 & .032 \\
Openness & & & & 2.769 & .288 & 4.799 & .000 \\
\hline
\end{tabular}

$* *=p<.01$

As seen in Table 2, against expectations however, openness to experience emerged as the strongest predictor of OCBI, followed by extraversion. Thus hypothesis 3 was not supported.

Table 3 Summary of Multiple-Regression Analysis for the Personality Dimensions and OCBO $(n=325)$

\begin{tabular}{|lccccccc|}
\hline \multicolumn{1}{|c}{ Predictor } & $\mathbf{R}$ & $\mathbf{R}^{2}$ & ANOVA & \multicolumn{4}{c|}{ Coefficients } \\
\hline Conscientiousnes & .478 & .229 & $23.716^{* *}$ & .350 & .046 & 0.773 & .440 \\
S & & & & & & & \\
Agreeableness & & & & .779 & .109 & 1.931 & .054 \\
Extraversion & & & & 1.045 & .159 & 2.949 & .003 \\
Openness & & & & 2.500 & .321 & 5.612 & .000 \\
\hline
\end{tabular}

$* *=p<.01$

With respect to OCBO too, Table 3 shows that openness to experience emerged as the strongest predictor, followed by extraversion. Thus hypothesis 4 was not supported either.

The explanation for these findings can be drawn from the study by King et al. (2005), which put forth the complex interplay within the personality traits, suggesting that single traits as predictors give an incomplete picture of their relationship with the outcome variables. More specifically, they argued that though agreeableness and conscientiousness may be necessary predictors of helping behaviors, any single trait cannot possess sufficient explanatory power, as interpersonal helping emerges from the motive to volunteer to help other people and the motive to engage in discretionary behaviors for the good of the organization (Hough, 1992; Organ, 1997). 
Though a mediator is often a person's psychological process in response to a stimulus (Hoyle \& Robinson, 2003), the personality factors of extraversion and openness to experience could reflect the motivational aspects mediating the relationship between conscientiousness and agreeableness on one hand, and OCB on the other. Thus path analysis testing for mediation was performed using the Baron and Kenny approach (Baron \& Kenny, 1986) with the help of Smart PLS. Biascorrected and accelerated (BCa) bootstrapping was run using a subsample of 5,000. The I.V. to mediator and mediator to D.V. Beta values, and their standard error values were then entered in the Daniel Soper online calculator for performing Sobel test.

Figure 1 Path Diagram for the Mediation Effect of Openness to Experience in the Relationship between Agreeableness and OCBI

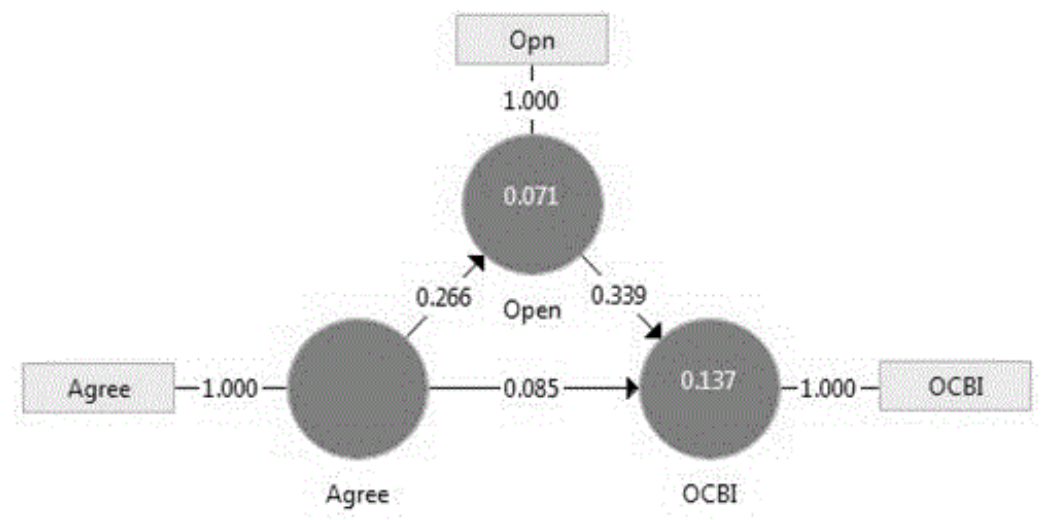

In Step 1 of the first mediation model tested, the regression of OCBI (D.V.) on agreeableness (I.V.), ignoring openness (the mediator), was not significant, $b=0.09, t=1.46, p>.05$. However, following Rucker et al. (2011), further mediation analysis was performed irrespective of lack of adherence to the requirement of significance of relationship between the I.V. (agreeableness) and D.V. (OCBI). Step 2 showed that the regression of openness on agreeableness was significant ( $b=0.27, t=5.20, p<.01$ ). Step 3 of the mediation process showed that the regression of OCBI on openness, controlling for agreeableness, was significant ( $b=0.34, t=5.83, p<.01$ ). Step 4 of the analyses revealed that controlling for openness rendered the direct effect of agreeableness on OCBI insignificant $(t=1.46)$. Sobel test statistics $(z=3.89, p<.01)$ confirmed that openness fully mediated the relationship between agreeableness and OCBI. 
Figure 2 Path Diagram for the Mediation Effect of Extraversion in the Relationship between Agreeableness and $\mathrm{OCBI}$

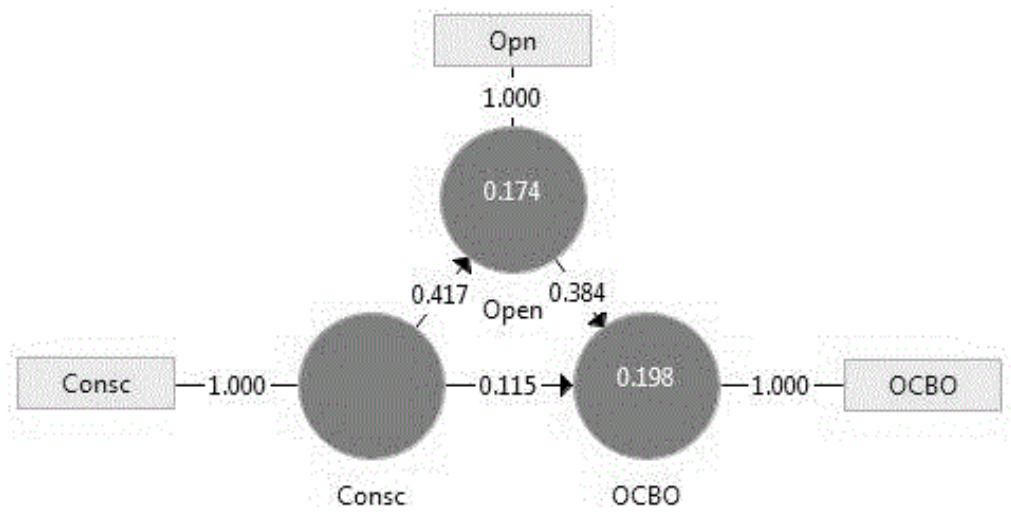

In Step 1 of the second mediation model tested, the regression of OCBI (D.V.) on agreeableness (I.V.), ignoring extraversion (the mediator), was significant, $b=0.13, t=2.44, p<.05$. Step 2 showed that the regression of extraversion on agreeableness too was significant $(b=0.18, t=$ 3.46, $p<.01$ ). Step 3 of the mediation process showed that the regression of OCBI on extraversion, controlling for agreeableness, was significant $(b=0.23, t=3.96, p<.01)$. Step 4 of the analyses revealed that even after controlling for extraversion, the direct effect of agreeableness on OCBI remained significant $(t=2.44)$. Sobel test statistics $(z=2.07, p<.05)$ too confirmed that extraversion partially mediated the relationship between agreeableness and OCBI.

Agreeableness encompasses a pro-social and communal orientation (John \& Srivastava, 1999) suggesting that highly agreeable employees would be more likely to engage in helping behaviors at the workplace, than individuals low on this trait. On the other hand, individuals high on extraversion are enthusiastic while engaging in the social world, are proactive, and tend to view others positively (John \& Srivastava, 1999). The findings of the study imply that employees, who are high on agreeableness but low on extraversion, may be reluctant to initiate social interactions spontaneously to help others.

Figure 3 Path Diagram for the Mediation Effect of Openness to Experience in the Relationship between Conscientiousness and OCBO

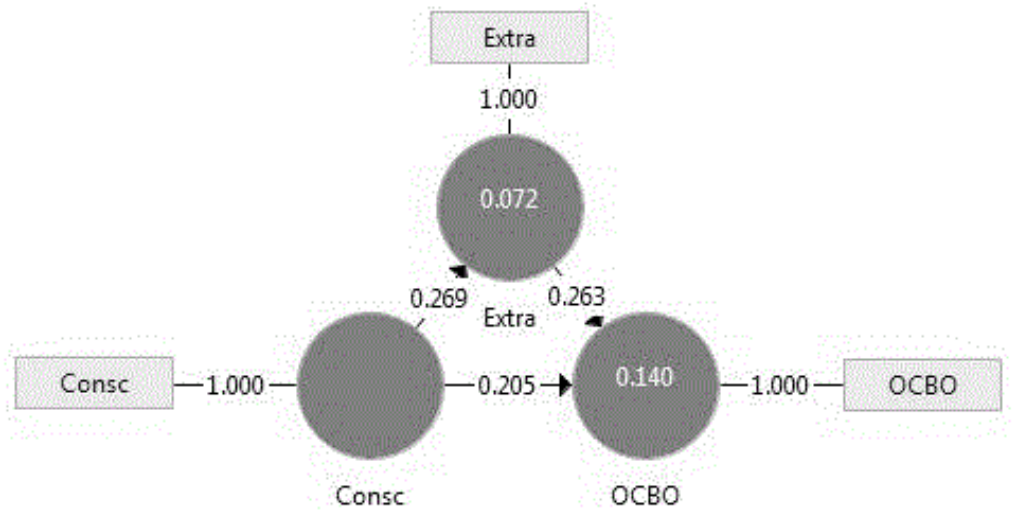


In the third mediation model tested, step 1 showed that the regression of OCBO (D.V.) on conscientiousness (I.V.), ignoring openness to experience (the mediator), was significant, $b=$ $0.12, t=1.99, p<.05$. Step 2 showed that the regression of openness on conscientiousness was also significant $(b=0.42, t=8.79, p<.01)$. Step 3 showed that the regression of OCBO on openness, controlling for conscientiousness, was significant $(b=0.38, t=6.47, p<.01)$. Step 4 of the analyses revealed that the direct effect of conscientiousness on OCBO remained significant $(t=1.99)$, even after controlling for openness. Sobel test statistics $(z=5.25, p<.01)$ too confirmed that openness partially mediated the relationship between conscientiousness and OCBO.

Figure 4 Path Diagram for the Mediation Effect of Extraversion in the Relationship between Conscientiousness and $\mathrm{OCBO}$

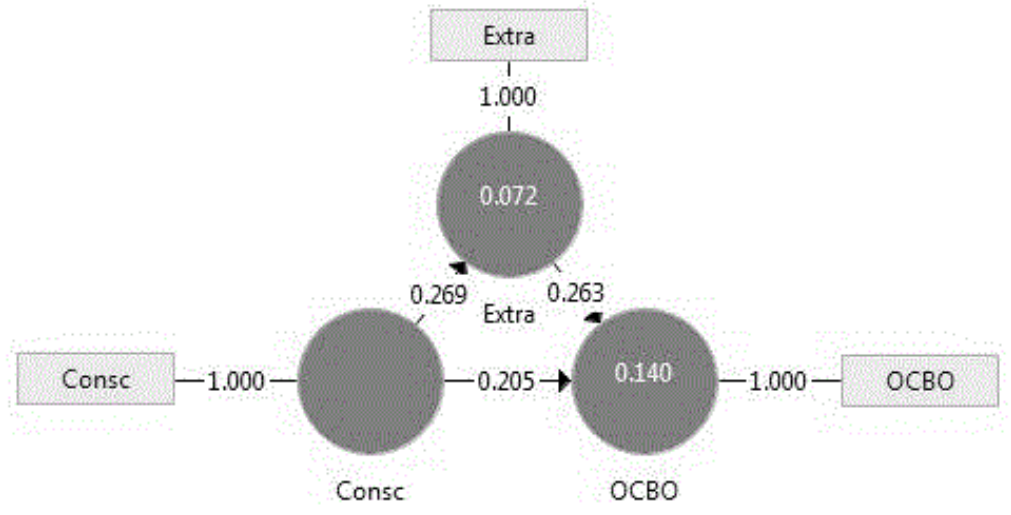

In the fourth mediation model tested, step 1 showed that the regression of OCBO (D.V.) on conscientiousness (I.V.), ignoring extraversion (the mediator), was significant, $b=0.21, t=3.71$, $p<.01$. In step 2 the regression of extraversion on conscientiousness was found to be significant too $(b=0.27, t=5.78, p<.01)$. Step 3 revealed that the regression of OCBO on extraversion, controlling for conscientiousness, was significant $(b=0.26, t=5.04, p<.01)$. Step 4 of the analyses revealed that the direct effect of conscientiousness on OCBO remained significant $(t=$ 3.71), even after controlling for extraversion. Sobel test statistics $(z=3.00, p<.01)$ confirmed that extraversion partially mediated the relationship between conscientiousness and OCBO.

The findings suggest that individuals scoring high on conscientiousness will be diligent, responsible, and dedicated and thus more likely to demonstrate OCBO; however, the motive required to voluntarily engage in behaviors in favor of the organization, may be reflected through the personality disposition of openness to experience. Similarly, a highly conscientious employee who is introverted may be reluctant to initiate citizenship behaviors directed towards the organization. To extent to which a highly conscientious employee also possess a positive interpersonal orientation, may better predict OCBO. 


\section{CONCLUSIONS}

Based upon the findings of the present study, the following conclusions may be drawn -

1. Conscientiousness, agreeableness, openness to experience and extraversion are positively correlated with both OCBI and OCBO.

2. Openness to experience is the strongest predictor of both OCBI and OCBO.

3. Openness to experience fully mediates the relationship between agreeableness and OCBI.

4. Extraversion partially mediates the relationship between agreeableness and OCBI.

5. Openness to experience partially mediates the relationship between conscientiousness and OCBO

6. Extraversion partially mediates the relationship between conscientiousness and OCBO.

\section{THEORETICAL AND PRACTICAL IMPLICATIONS}

There exists a plethora of studies linking dispositions and citizenship behaviors; however, attempts to study OCB beyond Organ's conceptualization have been only modest. Moreover, studies have generally focused on single traits as predictors of outcomes. However, given that personality is composed of multiple traits, and in the light of the findings of the present study, further studies in this area may consider how traits may work together to influence OCB. The present study has implications for personality theorists and researchers, as well as for HR personnel, considering the growing concern of rising turnover rates. The findings of the present study bring about the importance of the personality dimensions, especially openness to experience and extraversion, as predictors of OCBI and OCBO, as well as significant mediators. The interplay of personality traits within an employee must be taken into account, rather than looking at traits as mutually exclusive predictors of organizational outcome behaviors. Theorists may consider development of combination models with different permutations and combinations of the Big Five traits (e.g. low extraversion - high openness, high extraversion - high openness, and so on). Organizations may consider these findings at the selection stage, as well at the stage of planning of citizenship-based training programs.

\section{LIMITATIONS AND FUTURE DIRECTIONS}

Considering the total number of bank clerical employees in India, the sample for the present study, though sufficient as per the various rules of thumb, is very small. To be in a position to generalize the findings of the study on a pan-India basis with a significant amount of confidence, a larger sample from other states too must be studied. Secondly, the size of branches in terms of staff strength selected for data collection was controlled for, but the amount of workload could not be quantitatively controlled for. Opportunities to exhibit OCB could change as a function of the magnitude of workload at the branch. The data collected emerges from self-report inventories, and thus the honesty of the responses given in terms of indulgence in citizenship acts may be questioned.

Taking into account the findings and limitations of the present study, further investigation to establish the nature of the obtained findings may be suggested. Firstly, the approach of 
investigating mediating effects of personality factors between other personality dimensions and outcome behaviors, may open a new avenue of research approach. Moreover, the approach may be extended to other workplace outcome behaviors and even in non-industrial setups (e.g. for predicting social behaviors in social psychology, for determining prognosis and psychotherapies in counseling and clinical psychology, in studies in experimental and cognitive psychology, and so on). The interplay of other demographic factors like gender and age, in combination with the dispositional factors may be studied as well.

\section{REFERENCES}

Barnard, C. (1938). The functions of the executive. Cambridge: Harvard University Press.

Baron, R. M., \& Kenny, D. A. (1986). The moderator-mediator variable distinction in social psychological research: Conceptual, strategic, and statistical considerations. Journal of Personality and Social Psychology, 51, 1173-1182.

Bateman, T. S., \& Organ, D. W. (1983). Job satisfaction and the good soldier: The relationship between affect and employee "citizenship." The Academy of Management Journal, 26(4), 587-595.

Borman, W. C., Penner, L. A., Allen, T. D., \& Motowidlo, S. J. (2001). Personality predictors of citizenship performance. International Journal of Selection and Assessment, 9(1), 5269.

Chen, X. P. (2005). Organizational citizenship behavior: A predictor of employee voluntary turnover. In D. L. Turnipseed (Ed.), Handbook of organizational citizenship behavior (pp. 435-454). New York: Nova Science.

Chiaburu, D. S., Oh, I. S., Berry, C. M., Li, N., \& Gardner, R. G. (2011). The Five-Factor Model of personality traits and organizational citizenship behaviors: A meta-analysis. Journal of Applied Psychology, 96(6), 1140-1166.

Dunlop, P. D., \& Lee, K. (2004). Workplace deviance, organizational citizenship behavior, and business unit performance: The bad apples do spoil the whole barrel. Journal of Organizational Behavior, 25, 67-80.

Garson, G. D. (2012). Testing statistical assumptions. Retrieved from http://www.statisticalassociates.com/assumptions.pdf

Graham, J. W. (1991). An essay on organizational citizenship behavior. Employee Responsibilities and Rights Journal, 4, 249-270.

Hough, L. M. (1992). The 'Big Five' personality variables - construct confusion: Description versus prediction. Human Performance, 5, 139-155.

Hoyle, R. H., \& Robinson, J. I. (2003). Mediated and moderated effects in social psychological research: measurement, design, analysis issues. In C. Sansone, C. Morf, \& A. T. Panter (Eds.), Handbook of methods in social psychology (pp. 213-233). Thousand Oaks, CA: Sage.

Hurtz, G. M., \& Donovan, J. J. (2000). Personality and job performance: The Big Five revisited. Journal of Applied Psychology, 85, 869-879. doi:10.1037/0021-9010.85.6.869 
Ilies, R., Fulmer, I. S., Spitzmuller, M., \& Johnson, M. D. (2009). Personality and citizenship behavior: The mediating role of job satisfaction. Journal of Applied Psychology, 94, 945-959. doi:10.1037/a0013329

John, O. P., Donahue, E. M., \& Kentle, R. L. (1991). The Big Five Inventory-Versions $4 a$ and 54. Berkeley: University of California, Berkeley, Institute of Personality and Social Research.

John, O. P., \& Srivastava, S. (1999). The Big-Five trait taxonomy: History, measurement, and theoretical perspectives. In L. A. Pervin \& O. P. John (Eds.), Handbook of personality: Theory and research (Vol. 2, pp. 102-138). New York: Guilford Press.

Katz, D., \& Kahn, R. L. (1966). The social psychology or organizations. New York: John Wiley \& Sons.

Katz, D., \& Kahn, R. L. (1978). The social psychology of organizations $\left(2^{\text {nd }}\right.$ ed.). New York: John Wiley \& Sons.

King, E. B., George, J. M., \& Hebl, M. R. (2005). Linking personality to helping behaviors at work: An interactional perspective. Journal of Personality, 73(3), 585-608. doi: 10.1111/j.1467-6494.2005.00322.x

Koys, D. J. (2001). The effects of employee satisfaction, organizational citizenship behavior, and turnover on organizational effectiveness: A unit 0 level, longitudinal study. Personnel Psychology, 54, 101-104. Retrieved from: http://dx.doi.org/10.1111/j.17446570.2001.tb00087.x.

Lee, K., \& Allen, N.J. (2002). Organizational citizenship behaviour and workplace deviance: The role of affect and cognitions. Journal of Applied Psychology, 87, 131-142.

Mossholder, K. W., Settoon, R. P., \& Henagan, S. C. (2005). A relational perspective on turnover: Examining structural, attitudinal, and behavioral predictors. Academy of Management Journal, 48, 607-618.

Mount, M. K., Barrick, M. R., \& Stewart, G. L. (1998). Five-factor model of personality and performance in jobs involving interpersonal interactions. Human Performance, 11, 145165.

Organ, D. W. (1988). Organizational citizenship behavior: The good soldier syndrome. Lexington, MA: LexingtonBooks.

Organ, D. W. (1997). Organizational citizenship behavior: It's construct clean-up time. Human Performance, 10, 85-97.

Organ, D. W., \& Ryan, K. (1995). A meta-analytic review of attitudinal and dispositional predictors of organizational citizenship behavior. Personnel Psychology, 48, 775-802.

Podsakoff, P. M., \& MacKenzie, S. B. (1994). Organizational citizenship behaviors and sales unit effectiveness. Journal of Marketing Research, 3(1), 351-363.

Podsakoff, P. M., MacKenzie, S. B., Paine, J. B., \& Bachrach, D. G. (2000). Organizational citizenship behaviors: A critical review of the theoretical and empirical literature and suggestions for future research. Journal of Management, 26(3), 513-563.

Ringle, Christian M., Wende, Sven, \& Becker, Jan-Michael. (2015). SmartPLS 3. Bönningstedt: SmartPLS. Retrieved from http://www.smartpls.com 
Rucker, D. D., Preacher, K. J., Tormala, Z. L., \& Petty, R. E. (2011). Mediation analysis in social psychology: Current practices and new recommendations. Social and Personality Psychology Compass, 5(6), 359-371. doi: 10.1111/j.1751-9004.2011.00355.x

Smith, C. A., Organ, D. W., \& Near, J. P. (1983). Organizational citizenship behavior: Its nature and antecedents. Journal of Applied Psychology, 68, 655-663.

Walz, S. M., \& Niehoff, B. P. (1996). Organizational citizenship behaviors and their effect on organizational effectiveness in limited-menu restaurants. In J. B. Keys \& L. N. Dosier (Eds.), Academy of Management Best Papers Proceedings (pp.307-311). Mahwah, New Jersey: Psychology Press.

Williams, L. J., \& Anderson, S. E. (1991). Job satisfaction and organizational commitment as predictors of organizational citizenship and in-role performance. Journal of Management, 17(3), 601-617.

Williams, Matt N., Grajales, Carlos Alberto Gómez, \& Kurkiewicz, Dason (2013). Assumptions of multiple regression: Correcting two misconceptions. Practical Assessment, Research and Evaluation, 18 (11). Retrieved from http://pareonline.net/getvn.asp?v=18\&n=11

Witt, L. A., Burke, L. A., Barrick, M. R., \& Mount, M. K. (2002). The interactive effects of conscientiousness and agreeableness on job performance. Journal of Applied Psychology, 87(1), 164-169. doi: 10.1037//21-9010.87.1.164

Yen, H. R., \& Niehoff, B. P. (2004). Organizational citizenship behaviors and organizational effectiveness: Examining relationships in Taiwanese banks. Journal of Applied Social Psychology, 34, 1617-1637.

\section{APPENDIX}

Correlation Matrix for all variables $(n=325)$

\begin{tabular}{|c|c|c|c|c|c|c|c|}
\hline & 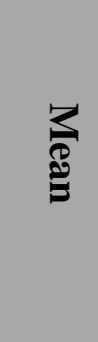 & $\tilde{\theta}$ & 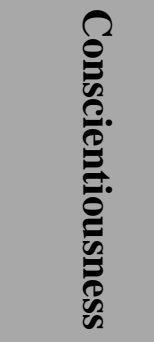 & 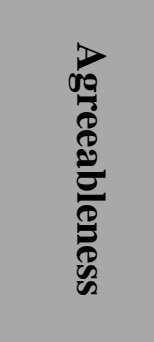 & 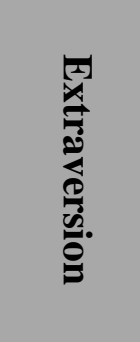 & 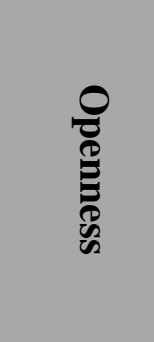 & 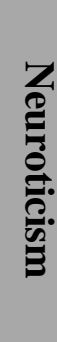 \\
\hline Conscientiousness & 4.12 & 0.57 & 1 & & & & \\
\hline Agreeableness & 4.06 & 0.60 & $.483^{* *}$ & 1 & & & \\
\hline Extraversion & 3.33 & 0.65 & $.269 * *$ & $.180 *$ & 1 & & \\
\hline Openness & 3.84 & 0.55 & $.417 * *$ & $.266^{* *}$ & $.395^{* *}$ & 1 & \\
\hline Neuroticism & 2.68 & 0.70 & $-.401 * *$ & $-.272 * *$ & $.234 * *$ & $-.231^{* *}$ & 1 \\
\hline
\end{tabular}

